\title{
BUILDING A EVALUATION OF PERFORMANCE MODEL FOR THE CLOUD E-LEARNING SERVICE USING HYBRID MCDM
}

\author{
Chiu-Hung Su \\ Department of Electrical Engineering, \\ Hwa Hsia Institute of Technology, Taiwan, \\ E-mail: chiuhung.su@gmail.com \\ Hao-Lin Tzeng \\ Institute of Logistics and Shipping Management, Kainan University \\ No. 1, Kainan Road, Luchu Shiang, Taoyuan 33857, Taiwan \\ E-mail: haolin.tseng@gmail.com \\ Gwo-Hshiung Tzeng* \\ Institute of Project Management, Kainan University \\ Kainan Rd., Luchu, Taoyuan 33857, Taiwan \\ Institute of Management of Technology, National Chiao Tung University \\ 1001, Ta-Hsueh Road, Hsinchu 300, Taiwan \\ E-mail: ghtzeng@cc.nctu.edu.tw; ghtzeng@mail.knu.edu.tw
}

\begin{abstract}
What is cloud e-learning service? It is an information revolution that is changing the computer usage habits of 1 billion people. An understanding of the intentions and behaviors of users with respect to cloud-service applications will be helpful for predicting whether the cloud-service applications in question will be adopted by the users and guiding the efforts of providers to enhance the functions of their software. A wide range of criteria are used to assess cloud elearning service applications, but most of these criteria have interdependent or interactive characteristics, which can make it difficult to effectively analyze and improve the services that are adopted by the users of these applications. The purpose of this study is to address this issue using a hybrid MCDM (multiple criteria decision-making) approach that includes the DEMATEL (decision-making trial and evaluation laboratory), DANP (DEMATEL-based analytic network process). By exploring the influential interrelationships between the criteria that impact the cloud e-learning service applications industry and its related value-added service content providers, this study can provide reference information with respect to operations. This approach can be used to solve interdependence and feedback problems, allowing for greater satisfaction of the actual needs of the cloud e-learning service applications industry.
\end{abstract}

Keywords: cloud Service Applications, cloud e-learning service, DANP (DEMATEL-based analytic network process), MCDM (multiple criteria decision-making), INRM

\section{Introduction}

These materials and resources are often various and abundant. It is a good thing to have all this stored information so close at hand. However, in the process of digital learning, it is up to the digital learner to choose his own materials. In these cases, the abundant information can actually cause more problems for

\footnotetext{
${ }^{*}$ Corresponding author
} 
some learners. During recent years designing and implementing web-based education (E-Learning) systems have grown dramatically (Hogo, 2010) and this type of education is playing an important role in teaching and learning (Franceschi, Lee, Zanakis, \& Hinds, 2009). Arbaugh (2002) defined e-learning as the use of the Internet by users to learn specific content. Other researchers define e-learning as using modern Information and Communications Technology (ICT) and computers to deliver instruction, information, and learning content (Selim, 2007). The purpose of the present study is to address this problem using the multiple criteria decision-making (MCDM) method to examine the dependent relationships among various dimensions and criteria related to passenger satisfaction and intentions to connection service and to ultimately suggest optimal improvement models. The first step is to construct a more integrated model of service evaluation systems. A DEMATEL technique is used to construct a network relation map (NRM), which is then used to illustrate the influential network of the determinants related to connection service. Subsequently, the DEMATEL-based ANP (called DANP) is employed to determine the influential weights of the criteria for further analysis. The remainder of this paper is organized as follows. In the next section, the literature pertaining to the link of metros and airports and the quality-satisfaction-intention paradigm are reviewed. Subsequently, a new hybrid MCDM evaluation model for connection service is developed, and an empirical case analysis of passenger consuming experiences illustrates the proposed model. Finally, the conclusion is presented.

\section{Literature review}

\subsection{Cloud Service Applications}

There are currently 6 main players in the Smartphone market, although Applees iOS and Google"s Android are dominating the market. [1] The main focus is on Smartphone software platform strategy, using the Smartphone as the market, and Apple and Google as case studies. As the network grows, the network not only becomes more desirable to buyers and sellers, but network efficiency drops as network participants have to spend more time to find each other (as in a dating network) or communication slows down (as in the case of a wireless network). The an app store has significant implications. As a store hosts more apps, more customers will be attracted to use the software.

Papers should be no longer than 6 pages, including references, appendices, figures, and tables. Tables and figures should be placed in the manuscript, close to where they are referenced. The paper should be written in Microsoft Word. We have observed that keeping papers on the shorter side usually improves the writing and makes the logic tighter, so we are maintaining a rather strict page limit. It is important that authors follow our instructions carefully. To help you in this task, we have written this document in the recommended format. It includes format styles to help put your paper in the format we request.

\subsection{Quality of Service, Information Quality, Management In the e-learning service context}

DeLone and McLean's (1992, 2003) information system (IS) success model is widely used to evaluate IS implementation. Many papers address the updated model consists of six constructs, which are net benefits, intention to use system, user satisfaction, and three independent variables including system quality, information quality and service quality (DeLone \& McLean, 2003). Some researcher discusses about the system quality in e-learning studies is defined as help functions and end-user facilitation in the education process. Information quality is defined as end-user performance improve resulting from using system information. Service quality is defined as support quality help to end-users to facilitate system usage (Wang \& Wang, 2009). Selim (2007) grouped E-Learning critical success factors to 4 categories include: instructor, student, Information Technology (IT) and university support. In our research, these factors were used to determine their effect on E-Learning outcomes.

\subsection{Quality of Service}

In this research, based on previous researches, therer are four major characteristics of teachers are used to measure this factor as following: motivation, attitude, training and teaching style(Abbas Keramati , Masoud Afshari-Mofrad , Ali Kamrani, 2011). Lee (2008) identifies some factors which influence e- 
learning be adopted based on perceived usefulness and perceived ease of use. Gagné (2008) found that perceived usefulness, perceived ease of use, and perceived playfulness are primary determinants of elearning continuance intention. Selim (2007) address the CSFs for e-learning into four factors based on student keep on observations including instructors' characteristics (teaching style, attitude toward students, technology control, etc.), students' characteristics (motivation, technical competency, perception of content and system, collaboration in interaction, etc.), technology (ease of access, internet speed, screen design, etc.), and institution support include those technical support, computer availability, learning material accessibility and printing, etc.. E-learning studies that the IS success model found that system quality and information quality would influence learner satisfaction (Chiu, Chui, \& Chang, 2007; Roca, Chiu, \& Martínez, 2006), performance expectation (Wu et al., 2010), perceived usefulness (Chen, 2010), and behavior intention to use e-learning systems (Lin, 2007). Service quality is the factor found to influence ease of use (Wang \& Wang, 2009), satisfaction (Lin, 2007; Roca et al., 2006). Chiu et al. (2007) reported that high information quality increases end-user system satisfaction while poorly designed elearning courses increases learner dropout. Ozkan and Koseler (2009) Perception for system quality increased the effectiveness of learning management systems while content quality created value and learner satisfaction. Technology has an important role in delivering learning outcomes because learners interact more in e-learning environments than with traditional face to face instruction (Webster \& Hackley, 1997). System design facilitates formative interactions, controls organizational activities, and provides correct and sufficient information to reduce uncertainty (Daft \& Lengel, 1986). System quality relates to a learner's belief about e-learning performance characteristics (Chiu et al., 2007) and is measured by functionality, ease of use, reliability, flexibility, data quality, portability, integration, and the importance (DeLone \& McLean, 2003). System quality has a strong positive effect on learners' satisfaction (Ozkan \& Koseler, 2009) and directly affects user beliefs (Davis, 1989). Factors that are relevant for infrastructure and system quality include Internet quality, facilitating conditions, reliability, ease of use, system functionality, system interactivity, system response, and equipment accessibility (Arbaugh, 2002; Sun et al., 2008; Teo, 2010; Wu et al., 2010).

\subsection{Information Quality}

Johnson et al. (2009) found that course utility, course satisfaction and course grade as E-Learning outcomes. For example, learner attitudes, instructor quality, system quality, information (content) quality, service quality and supporter important factors for learners' satisfaction (Ozkan\&Kosele, , 2009). Govindasamy (2002) reported some factors for e-learning implementation including institutional support, faculty support, student support, teaching and learning, course structure, evaluation and assessment. Different aspects of e-learning have been examined in developing learning including technology-based components (Islas et al., 2007), student and teacher satisfaction (Liaw,Huang,\&Chen, 2007), the effectiveness of e-learning (Douglas\&Vyver, 2004), students' interaction in an online environment (Arbaugh \& Fich, 2007), and the student experience (Gilbert, 2007). Brophy reported well-designed courses, curriculum, and learning materials facilitate meaningful educational experiences (Brophy, 2000). Information quality is defined as the accuracy, completeness, ease of understanding, and relevance of online course materials (Chiu et al., 2007;). DeLone \& McLean address information quality is measured in terms of accuracy, timeliness, completeness, relevance, and consistency (DeLone \& McLean, 2003). Learning is a complicated activity because in addition to teaching skills, curriculum and teaching resources influence the learning process (Sharma \& Kitchens, 2004). Ozkan and Koseler (2009) reported information quality has a strong positive effect toward learners' satisfaction. Characteristics of information quality include content relevance, course quality, and course flexibility (Arbaugh, 2002; McKinney et al., 2002; Sun et al., 2008).

\subsection{Management}

When the corporation is caught in the process of R\&D, a large amount of human resources and capital is always in great demand and thus, the cost may certainly impact on the corporation's finance. In this case, 
outsourcing helps the corporation to reduce the cost spent on R\&D and break into a new market. By investing the capital in the products beneficial to the corporation, it is more likely to increase its advantages in the market. Moreover, it may maximize its niche market by managing its finance well and making the most of its limited capital. On the other hand, outsourcing helps the corporation to reduce the risks of stepping into a new market in a rush so that its investments will not be in vain. Outsourcing can be also a mechanism to adjust an organization to the market when the corporation is experiencing organization reengineering or reconstruction due to the downsized business or market(Akomode et al., 1998;Sparrow, 2003; Barthélemy et al., 1993 ; Sood, 2005; Alexander et al., 1996).

\section{Methodology}

Tzeng and Huang (2011) indicate that the multiple criteria decision-making (MCDM) method can consider multiple criteria simultaneously and assist decision-makers in estimating the best solutions according to the characteristics of the limited available cases. First, the DEMATEL was used to confirm the effect on each criterion and to explore the relevance of the connection service parameters. Subsequently, the DANP approach, which is a novel combination of the DEMATEL and the ANP method based on the concepts of Saaty (1996), was adopted to calculate the weight of the criteria.

\subsection{Evaluation criteria and data collection}

A list of factors was found in the literature, as discussed above. These factors are included as the evaluation criteria of this study and incorporated into the design of the hybrid MCDM survey, which included three dimensions and twelve criteria (see Table 1).

Because this survey is focused on cloud e-learning service Applications, the perspectives regarding the assessment criteria were received from domain experts through personal interviews and completed surveys. The expert group is comprised of 30 expert users who employed Cloud Service Applications. Among these experts, 14 individuals are experienced cloud e-learning service Applications leaders, 6 individuals are officials from the Cloud Service Applications departments of government, and the remaining 10 individuals are e-learning service scholars. The survey collected the ratings of these experts for each criterion using a 5-point scale ranging from 0 (no effect) to 4 (extremely influential). A total of 30 surveys were obtained during the period from May 2012 to July 2012. Each interview conducted with an expert was approximately 40 to 50 minutes in duration, and the surveys were collected at the end of the interviews.

\subsection{Building a network relationship using the DEMATEL technique}

The DEMATEL is commonly used to solve such problems in MCDM. The DEMATEL technique is used in this study to display the direct/indirect influential relationships in the subsystems because this display assists in developing a complete decision model. This technique uses matrix calculations to obtain all of the direct and indirect influential relationships and the strength of the effect. A visual structural matrix and influence diagram is used to show the influential relationship and level of influence between the criteria in a complex system (Chen et al., 2011; Huang et al., 2011; Huang et al., 2007; Yang and Tzeng, 2011).

\subsection{Using DANP to determine the influence of weights}

After the DEMATEL confirms the influential relationships between the criteria, the DANP is used to obtain their most accurate weights. The ANP presented by Saaty (1996) aims to decrease the limitations associated with the analytic hierarchy process (AHP) and thus creates a solution for determining nonlinear and complex network relationships. Therefore, this research supplements DEMATEL with the strength of the ANP to solve the dependence and feedback problems associated with the interrelation between the criteria (Kuan et al., 2011; Chen et al., 2011). Saaty proposed a method for the analysis of the ANP by adopting the limiting-process method of the powers of the supermatrix (Sekitani and Takahashi, 2001). Although the ANP can theoretically be used for the treatment of interdependencies, it is wise to first adopt the DEMATEL technique to generate an influential relationship. The treatment of interdependencies in the unweighted supermatrix requires the use of the DEMATEL. Thus, a hybrid MCDM model that combines the DEMATEL technique with the ANP (DANP) method can be used to solve the dependence and feedback problems. This combined method has been successfully used in various fields 
for uses that include e-learning evaluation (Tzeng et al., 2007). To gain valuable decision-making information, the DEMATEL is first used to draw a relationship diagram for cloud e-learning service. The DANP is then utilized to determine the influential weights of the evaluation criteria and prioritize them accordingly.

Table 1. The dimensions and criteria associated with cloud e-learning service.

\begin{tabular}{|c|c|c|}
\hline Dimensions/Origin & Criteria & Evaluated Item \\
\hline \multirow[t]{5}{*}{ Quality of Service } & Computer training & $\begin{array}{l}\text { The cloud e-learning service provides computer } \\
\text { training. }\end{array}$ \\
\hline & Program flexibility & $\begin{array}{l}\text { The cloud e-learning service provides program } \\
\text { flexibility of modifily. }\end{array}$ \\
\hline & Easy to use & It is easy to use cloud computing services. \\
\hline & Connection rate & Availability of high-speed computing service. \\
\hline & System stability & $\begin{array}{l}\text { Collecting data using cloud computing to increase } \\
\text { work efficiency. }\end{array}$ \\
\hline \multirow[t]{4}{*}{ Information Quality } & Quality of courses & Quality of courses after the use of cloud computing. \\
\hline & $\begin{array}{l}\text { Flexibility of } \\
\text { courses }\end{array}$ & $\begin{array}{l}\text { The cloud e-learning service provides flexibility of } \\
\text { courses. }\end{array}$ \\
\hline & $\begin{array}{l}\text { Contents meet the } \\
\text { needs }\end{array}$ & $\begin{array}{l}\text { The contents of the cloud e-learning service meet the } \\
\text { needs. }\end{array}$ \\
\hline & $\begin{array}{l}\text { Interactive } \\
\text { environment }\end{array}$ & Digital learning provides an interactive environment. \\
\hline \multirow[t]{3}{*}{ Management } & Customized & $\begin{array}{l}\text { Cloud service suppliers provide customized services } \\
\text { in cloud services adoption }\end{array}$ \\
\hline & Reduce the cost & Cloud service provides reduced the cost. \\
\hline & Risk-sharing & $\begin{array}{l}\text { Using cloud services to share the risk of business } \\
\text { operations. }\end{array}$ \\
\hline
\end{tabular}

\section{Empirical case analysis of the E-Learning}

This section assesses the overall E-Learning to propose improvement strategies using an empirical case, the E-Learning in Taiwan. The data collected from expert users are analyzed by a hybrid MCDM method, and the results are presented in useful decision-making models.

\subsection{Description of the problems}

The rapid growth of information technology has made digital learning exceed the limitations of space and time, resulting in the transfer of knowledge at a faster pace. For this reason, digital learning has become a new addition to the field of multi-media. Looking at the field of digital learning and research in both domestic and overseas areas, is observed that most focus is put on the media content while the learners of these digital tools are being neglected. This will influence digital learner motivation. Teaching materials are increasing at exponential rates that far exceed the rate of learners who can absorb them. In order to offer a suggestion on the development strategy to the manufacturer, the research of the future development for E-Learning is necessary.

4.2 Constructing the network relation map using the DEMATEL

According to the questionnaires completed by the experts (30 samples of experts), the initial matrix A is obtained by pair wise comparison, through which a normalized matrix D is derived and is available for calculating the total effect matrix $\mathrm{T}$ of the criteria. The result is highly significant confidence (reliable), with a high consistency ratio of $96 \%$ (larger than $95 \%$; error ratio in gap $=0.036<5 \%$, referring to note beneath Table 2 in footnote), and serves to derive the sum of influences given and received on the criteria (Table 2).

Table 2 Total influential effect matrix Tc of criteria

$$
\begin{array}{|l|lllll|llll|lll|}
\hline T_{c} & C_{11} & C_{12} & \mathrm{C}_{13} & \mathrm{C}_{14} & \mathrm{C}_{15} & \mathrm{C}_{21} & \mathrm{C}_{22} & \mathrm{C}_{23} & \mathrm{C}_{24} & \mathrm{C}_{31} & \mathrm{C}_{32} & \mathrm{C}_{33} \\
\hline
\end{array}
$$




\begin{tabular}{|l|lllll|llll|lll|}
\hline $\boldsymbol{C}_{\mathbf{1 1}}$ & 0.093 & 0.166 & 0.187 & 0.021 & 0.129 & 0.211 & 0.080 & 0.100 & 0.058 & 0.117 & 0.071 & 0.055 \\
$\mathbf{C}_{\mathbf{1 2}}$ & 0.159 & 0.074 & 0.087 & 0.015 & 0.035 & 0.126 & 0.056 & 0.053 & 0.064 & 0.114 & 0.042 & 0.051 \\
$\mathbf{C}_{\mathbf{1 3}}$ & 0.233 & 0.271 & 0.118 & 0.030 & 0.143 & 0.261 & 0.217 & 0.208 & 0.135 & 0.195 & 0.125 & 0.099 \\
$\mathbf{C}_{\mathbf{1 4}}$ & 0.279 & 0.288 & 0.265 & 0.036 & 0.198 & 0.309 & 0.219 & 0.192 & 0.128 & 0.278 & 0.235 & 0.109 \\
$\mathbf{C}_{\mathbf{1 5}}$ & 0.239 & 0.234 & 0.173 & 0.113 & 0.068 & 0.230 & 0.125 & 0.098 & 0.077 & 0.208 & 0.175 & 0.078 \\
\hline $\mathbf{C}_{\mathbf{2 1}}$ & 0.183 & 0.266 & 0.196 & 0.021 & 0.056 & 0.145 & 0.218 & 0.190 & 0.167 & 0.215 & 0.171 & 0.130 \\
$\mathbf{C}_{\mathbf{2 2}}$ & 0.161 & 0.274 & 0.170 & 0.024 & 0.056 & 0.253 & 0.115 & 0.216 & 0.162 & 0.250 & 0.149 & 0.209 \\
$\mathbf{C}_{\mathbf{2 3}}$ & 0.060 & 0.040 & 0.033 & 0.011 & 0.018 & 0.065 & 0.056 & 0.025 & 0.019 & 0.038 & 0.023 & 0.049 \\
$\mathbf{C}_{\mathbf{2 4}}$ & 0.120 & 0.231 & 0.160 & 0.050 & 0.056 & 0.185 & 0.183 & 0.097 & 0.068 & 0.234 & 0.170 & 0.170 \\
\hline $\mathbf{C}_{\mathbf{3 1}}$ & 0.213 & 0.263 & 0.155 & 0.020 & 0.059 & 0.162 & 0.145 & 0.171 & 0.089 & 0.112 & 0.154 & 0.186 \\
$\mathbf{C}_{\mathbf{3 2}}$ & 0.081 & 0.086 & 0.092 & 0.047 & 0.093 & 0.164 & 0.065 & 0.058 & 0.074 & 0.102 & 0.054 & 0.078 \\
$\mathbf{C}_{\mathbf{3 3}}$ & 0.091 & 0.193 & 0.134 & 0.011 & 0.040 & 0.151 & 0.158 & 0.107 & 0.055 & 0.200 & 0.073 & 0.065 \\
\hline
\end{tabular}

Note: ${ }^{\frac{1}{n^{2}} \sum_{i=1}^{n} \sum_{j=1}^{n} \frac{t_{i j}^{p}-t_{i j}^{p-1} \mid}{t_{i j}^{p}} \times 100 \%}=4 \%<5 \%$, significant confidence is $96 \%$ more than $95 \%$, where $t_{i j}^{p}$ and $t_{i j}^{p-1}$ denote the average influence of $\mathrm{i}$ criterion to $\mathrm{j}$ by $\mathrm{p}$ samples and $\mathrm{p}-1$ samples respectively; $\mathrm{n}$ denotes the numbers of criteria.

\section{Conclusions}

This research modeled the strategies that should be pursued to improve the connection service to the urban airport in Taipei. A novel hybrid MCDM method was used to address the dependent relationships among the various criteria together with DEMATEL (used to construct the NRM), the DANP (used to determine the relative weights of the criteria) .

The empirical test of our approach, which was conducted using a case study of the e-learning service factor from the Taiwan, illustrated the usefulness of the approach in accounting for complex e-learning service components and the meaningful implications of our study for decision-makers. Overall, the results and implications may be valuable for both practitioners and researchers and for those destinations attempting to expand the e-learning development.

However, there are some limitations in this research. First, this study was conducted with relatively expert sample groups. A larger sample with more explanatory power would have allowed a more sophisticated evaluation analysis and verified the current findings to increase generalize ability. Second, the evaluation criteria were selected from a review of the literature on e-learning service. Other methodologies, such as longitudinal studies and in-depth interviews, could have been applied to identify other possible criteria. Thus, further research in the field is necessary in terms of developing more elaborated multi-criteria structure that incorporates a large sample using the hybrid MCDM methods.

\section{REFERENCES}

Akomode, O. J., Lees, B. and Irgens, C. (1998). Constructing customised models and providing information for IT outsourcing decisions. Logistics Information Management, 11(2), 114-127.

Alexander, M. and Young, D. (1996b). Outsourcing: Where's the value?. Long Range Planning, 29(5), 728-730.

Alexander, M. and Young, D. (1996). Strategic outsourcing. Long Range Planning, 29(1), 116-119.

Arbaugh, J. B. (2000). Virtual classroom characteristics and student satisfaction with internet-based MBA courses. Journal of Management Education, 24(1), 32-54. 
Arbaugh, J.B.(2002). Managing the on-line classroom: a study of technological and behavioral characteristics of web-based MBA courses. Journal of High Technology Management Research, 13(2), 203-223.

Arbaugh, J. B., \& Duray, R. (2002). Technological and structural characteristics, student learning and satisfaction with web-based courses - an exploratory study of two on-line MBA programs. Management Learning, 33(3), 331-347.

Arbaugh, J. B., \& Fich, R. B. (2007). The importance of participant interaction in online environments. Decision Support Systems, 43(2), 853-865.

Barthélemy, J. and Adsit, D. (1993). The seven deadly sins of outsourcing. The Academy of Management Executive, 17(2), 87-100.

Brophy, J. (2000). Teaching. Geneva, Switzerland: PCL, Lausanne.

Chen, F.H., Tzeng, G.H., Hsu, T.S. A balanced scorecard approach to establish a performance evaluation and relationship model for hot spring hotels based on a hybrid MCDM model combining DEMATEL and ANP. International Journal of Hospitality Management, in press. , 2011.

Chen, H.-J. (2010). Linking employees' e-learning system use to their overall job outcomes: an empirical study based on the IS success model. Computers \& Education, 55(4),1628-1639.

Chiu, C.-M., Chiu, C.-S., \& Chang, H.-C. (2007). Examining the integrated influence of fairness and quality on learners' satisfaction and web-based learning continuance intention. Information Systems Journal, 17(3), 271-287.

Daft, R. L., \& Lengel, R. H. (1986). Organizational information requirements, media richness and structural design. Management Science, 32(5), 554-571.

Davis, F. D. (1989). Usefulness, perceived ease of use, and user acceptance of information technology. MIS Quarterly, 13(3), 319-340.

DeLone, W. H., \& McLean, E. R. (1992). Information systems success: the quest for the dependent variable. Information Systems Research, 3(1), 60-95.

DeLone,W. H., \& McLean, E. R. (2003). The DeLone and McLean model of information systems success: a ten-year update. Journal of Management Information Systems, 19(4), 9-30.

Douglas, E., \& Vyver, G. V. D. (2004). Effectiveness of e-learning course materials for learning database management systems: an experimental investigation. Journal of Computer Information Systems, 41(4), $41-48$.

Fill, C. and Visser, E. (2000). The outsourcing dilemma: a composite approach to the make or buy decision. Management Decision, 38(1), 43-50.

Franceschi, K., Lee, R. M., Zanakis, S. H., \& Hinds, D. (2009). Engaging group E-learning in virtual worlds. Journal of Management Information Systems, 26(1), 73-100.

Gilbert, J. (2007). e-learning: the student experience. British Journal of Education Technology, 38(4), 560-573.

Govindasamy, T. (2002). Successful implementation of e-Learning pedagogical considerations. Internet and Higher Education, 4(3-4), 287-299.

Hogo, M. A. (2010). Evaluation of E-learning systems based on fuzzy clustering models and statistical tools. Expert Systems with Applications, 37(10), 6891-6903.

Huang, C.Y., Shyu, J.Z., Tzeng, G.H., Reconfiguring the innovation policy portfolios for Taiwan's SIP mall industry. Technovation 27(12), 744-765. 2007.

Islas, E., Perez, M., Rodriguez, G., Paredes, I., Avila, I., \& Mendoza, M. (2007). E-learning tools evaluation and roadmap development for an electrical utility. Journal of Theoretical and Applied Electronic Commerce Research, 2(1), 63-75.

Johnson, R. D., Gueutal, H., \& Cecilia, M. F. (2009). Technology, trainees, metacognitive activity and ELearning effectiveness. Journal of Managerial Psychology, 24(6), 545-566.

Keramati A, Afshari-Mofrad M, Kamrani A , Ali Kamrani.The role of readiness factors in E-learning outcomes: An empirical study.Computers \& Education 57 (2011) 1919-1929. 
Kuan, M.J., Hsiang, C.C., Tzeng, G.H., Probing the innovative quality system structure model for NPD Process based on combining DANP with MCDM Model. International Journal of Innovative Computing. Information and Control, forthcoming. 2011.

Lee, Y.-C. (2008). The role of perceived resources in online learning adoption. Computers \& Education, 50(4), 1423-1438.

Liaw, S. S., Huang, H. M., \& Chen, G. D. (2007). Surveying instructor and learner attitudes toward elearning. Computers \& Education, 49(4), 1066-1080.

Lin, H.-F. (2007). Measuring online learning systems success: applying the updated DeLone and McLean model. Cyberpsychology and Behavior, 10(6), 817-820.

McKinney, V., Yoon, K., \& Zahedi, F. M. (2002). The measurement of web-customer satisfaction: an expectation and disconfirmation approach. Information Systems Research, 13(3), 296-315.

Meyer, J. P., \& Gagne, M. (2008). Employee engagement from a self-determination theory perspective. Industrial and Organizational Psychology, 1(1), 60-62.

Ozkan, S., \& Koseler, R. (2009). Multi-dimensional students' evaluation of e-learning systems in the higher education context: an empirical investigation. Computers \& Education, 53(4), 1285-1296.

Roca, J. C., \& Gagne, M. (2008). Understanding e-learning continuance intention in the workplace: a selfdetermination theory perspective. Computers in Human Behavior, 24(4), 1585-1604.

Roca, J. C., Chiu, C.-M., \& Martinez, F. J. (2006). Understanding e-learning continuance intention: an extension of the technology acceptance model. International Journal of Human-Computer Studies, 64(8), 683-696.

Saaty, T.L. Decision making with dependence and feedback: The Analytic Network Process. RWS Publications, Pittsburgh., 1996.

Sekitani, K., Takahashi, I. A unified model and analysis for AHP and ANP. Journal of the Operations Research Society of Japan 44 (1), 67-89. , 2001.

Selim, H. M. (2007). Critical success factors for E-learning acceptance: confirmatory factor models. Computers \& Education, 49(2), 396-413.

Sharma, S. K., \& Kitchens, F. L. (2004). Web services architecture for e-learning. Electronic Journal on e-learning, 2(1), 203-216.

Sood, R. IT (2005). software and services: outsourcing \& offshoring. Austin, Texas: AiAiYo Books.

Sparrow, E. (2003). Successful IT outsourcing: from choosing a provider to managing the project. London: Springer-Verlag.

Sun, P.-C., Tsai, R. J., Finger, G., Chen, Y.-Y., \& Yeh, D. (2008). What drives a successful e-learning? An empirical investigation of the critical factors influencing learner satisfaction. Computers \& Education, 50(4), 1183-1202.

Teo, T. (2010). Development and validation of the E-learning Acceptance Measure (ElAM). Internet and Higher Education, 13(3), 148-152.

Tzeng, G. H., Huang, J.J., Multiple attribute decision making: Methods and applications. Taylor \& Francis. 2011.

Tzeng, G.H., Cheng, H.J., Huang, T.D. Multi-objective optimal planning for designing relief delivery systems. Transportation Research Part E: Logistics and Transportation Review 43(6), 673-686. 2007.

Wang, W.-T., \& Wang, C.-C. (2009). An empirical study of instructor adoption of web-based learning systems. Computers \& Education, 53(3), 761-774.

Webster, J., \& Hackley, P. (1997). Teaching effectiveness in technology-mediated distance learning. The Academy of Management Journal, 40(6), 1282-1309.

Wu, J.-H., Tennyson, R. D., \& Hsia, T.-L. (2010). A study of student satisfaction in a blended e-learning system environment. Computers \& Education, 55(1), 155-164.

Yang, J.L., Tzeng, G.H., An integrated MCDM technique combined with DEMATEL for a novel clusterweighted with ANP method. Expert Systems with Applications 38(3), 1417-1424., 2011. 